\title{
THE ISOLATION AND SOME PROPERTIES OF NEW FLAVINS ("SCHIZOFLAVIN") FORMED BY SCHIZOPHYLLUM COMMUNE
}

\author{
Sei Tachibana and Toshio Murakami ${ }^{1}$ \\ Department of Chemistry, Faculty of Science and Engineering, \\ Ritsumeikan University, Kita-ku, Kyoto
}

(Received September 18, 1974)

It has been reported that a new flavin (X) was found in the culture broth of Schizophyllum commune, and that some properties of $\mathrm{X}$ were examined (1). Recently, another new flavin (Y) was detected in the broth of this mold containing FR (2). There is evidence, however, that $\mathrm{Y}$ might be a ghost spot of FR on paper chromatograms when the culture filtrate was used as a sample for paper chromatography. In the present study, we isolated the new flavins, $\mathrm{Y}$ and $\mathrm{X}$, formed by $S$. commune and examined mainly some properties of $\mathrm{Y}$, comparing them to those of $\mathrm{X}$ or several known flavins.

The basal medium employed was composed of $5 \mathrm{~g}$ glucose, $0.3 \mathrm{~g}$ meat extract, $0.2 \mathrm{~g}$ polypeptone, $0.1 \mathrm{~g} \mathrm{KH}_{2} \mathrm{PO}_{4}, 0.05 \mathrm{~g} \mathrm{MgSO}_{4} \cdot 7 \mathrm{H}_{2} \mathrm{O}, 0.05 \mathrm{~g} \mathrm{KCl}, 0.13 \mathrm{mg}$ $\mathrm{MnCl}_{2}, 0.5 \mu \mathrm{g}$ thiamine, and $100 \mathrm{ml}$ tap water. FR of $150 \mathrm{mg}$ was added to 1.5 liter of the medium in a 5 liter-Erlenmyer flask before sterilization. S.commune IFO No. 4928 was cultured statically in the dark for 3 weeks at $30^{\circ} \mathrm{C}$. After cultivation, the new flavins were purified by CRAMMER's method (3), paper chromatography, ion exchange method (Amberlite IR-120B), and gel filtration (Sephadex G-15) from the culture filtrate. Both the $\mathrm{Y}$ and $\mathrm{X}$ solutions obtained had yellowish green fluorescence and were reduced by sodium dithionite and reversibly oxidized by air.

Table 1 shows the paper chromatographic and electrophoretic behaviours of Y. Y had slightly larger $R f$ values than FR in all cases of the four developers. On paper chromatograms developed with the upper layer of $n$-butanol-acetate-water (4: $1: 5)$ which is favourable for the detection of flavin compounds, $Y$ was almost indistinguishable from FR. To separate from FR or several known flavins more clearly $\mathrm{Y}$, a solvent system consisting of $n$-butanol-pyridine-water $(6: 4: 3)$ was used: $R f$ values, Y 0.56; X 0.18; FR 0.51; FMN 0.07; FAD 0.04. On electrophore-

\section{1 立花 精, 村上俊男}

2 Abbreviations used are: FR, riboflavin; F-gl, riboflavinylglucoside; RCMP, riboflavin cyclic monophosphate; RDP, riboflavin diphosphate; RCDP, riboflavin cyclic diphosphate; Lf, lumiflavin; 8-DMLf, 8-demethyllumiflavin; Lc, lumichrome; SD, succinate dehydrogenase. 
Table 1. Paper chromatographic and electrophoretic behaviours of flavin compounds. Paper chromatography was carried out using the ascending method.

The paper electrophoresis was carried out under constant voltage $(200 \mathrm{~V})$ using $0.05 \mathrm{M}$ phosphate buffer.

\begin{tabular}{lcccccc}
\hline & \multicolumn{3}{c}{$R f$} & \multicolumn{2}{c}{ Mobility (mm) } \\
\cline { 2 - 7 } & $\mathrm{Bu}, \mathrm{Py}, \mathrm{W}^{\mathrm{a}}$ & $\mathrm{Bu}, \mathrm{Ac}, \mathrm{W}^{\mathrm{a}}$ & $\mathrm{W} \cdot$ iso- $^{\mathrm{a}}$ & $\mathrm{Na}_{2} \mathrm{HPO}_{4}{ }^{\mathrm{a}}$ & $\mathrm{pH} 5.9$ & $\mathrm{pH} \mathrm{8.0}$ \\
\hline Y & 0.56 & 0.34 & 0.50 & 0.36 & -5 & -4 \\
X & 0.18 & 0.30 & 0.88 & 0.40 & +21 & +10 \\
FR & 0.51 & 0.33 & 0.47 & 0.34 & -5 & -4 \\
FMN & 0.07 & 0.11 & 0.90 & 0.60 & +26 & +23 \\
FAD & 0.04 & 0.04 & & 0.45 & +30 & +18 \\
Lf & & 0.43 & 0.30 & & & -4 \\
F-gl & 0.32 & 0.23 & 0.55 & & & \\
RCMP & & 0.11 & & & & \\
RDP b & & 0.04 & & & & \\
RCDP & & 0.18 & & & & \\
\hline
\end{tabular}

a Solvent systems used are: $\mathrm{Bu}, \mathrm{Py}, \mathrm{W}, n$-butanol-pyridine-water (6:4:3); Bu, Ac, W, $n$ butanol-acetate-water (4: 1:5, upper layer); W-iso-A, water saturated with iso-amyl alcohol; $\mathrm{Na}_{2} \mathrm{HPO}_{4}, 5 \%$ aqueous $\mathrm{Na}_{2} \mathrm{HPO}_{4} \cdot 12 \mathrm{H}_{2} \mathrm{O}$.

b RCMP (4) and RDP (5) were formed by Rhizopus sp., and RCDP (6) was by Aspergillus sp.

sis, Y spot moved slightly toward the cathode just as FR, either at $\mathrm{pH} 5.9$ or at $\mathrm{pH}$ 8.0. The ultraviolet and visible absorption spectra of the flavins were measured in water, $0.05 \mathrm{~N}$ sodium hydroxide, and $3 \mathrm{~N}$ hydrochloric acid, respectively. As shown in Fig. 1, the absorption peaks of Y or X were at 223, 267, 374, and $446 \mathrm{~nm}$, being agreed very closely with those of FR. Significant shifts of the peaks of Y, X, and FR were not observed in acidic or alkaline region. These results suggest that both $\mathrm{Y}$ and $\mathrm{X}$ have 7,8-dimethylisoalloxazine moiety, as well as FR. However, the three flavins differed from one another in the absorption ratios (Fig. 1). These differences, in addition to the differences in the $R f$ values and the mobilities among $\mathrm{Y}, \mathrm{X}$ and several known flavins, must be due to the differences in their 10-side chains. The fluorescence spectra of $Y, X, F R$, and FMN were measured at an excitation wavelength of $370 \mathrm{~nm}$. The maximum intensity was observed at an emission wavelength of $525 \mathrm{~nm}$ in all samples tested. Next, the relationship between intensity of fluorescence and $\mathrm{pH}$ was determined by measuring the emission intensity of $\mathrm{Y}, \mathrm{X}$, and FR at various pHs. There was no significant difference in the pattern of fluorescence-pH curves among the three flavins. From the above spectroscopic analyses, both $\mathrm{Y}$ and $\mathrm{X}$ were ascertained as not having a structure with the alkaline nitrogen atom bound to the 7- or 8-methyl group as SD-flavin (7), or such degradation products as Lc and 8-DMLf (8). In order to verify this, the two new flavins were exposed to half shaded sunlight for $2 \mathrm{hr}$. Both Y and $\mathrm{X}$ were photolyzed to $\mathrm{Lf}$ (in the alkaline state) or Lc (in the acidic state).

Some properties of the second flavin, $\mathrm{Y}$ formed by $S$. commune, were ex- 


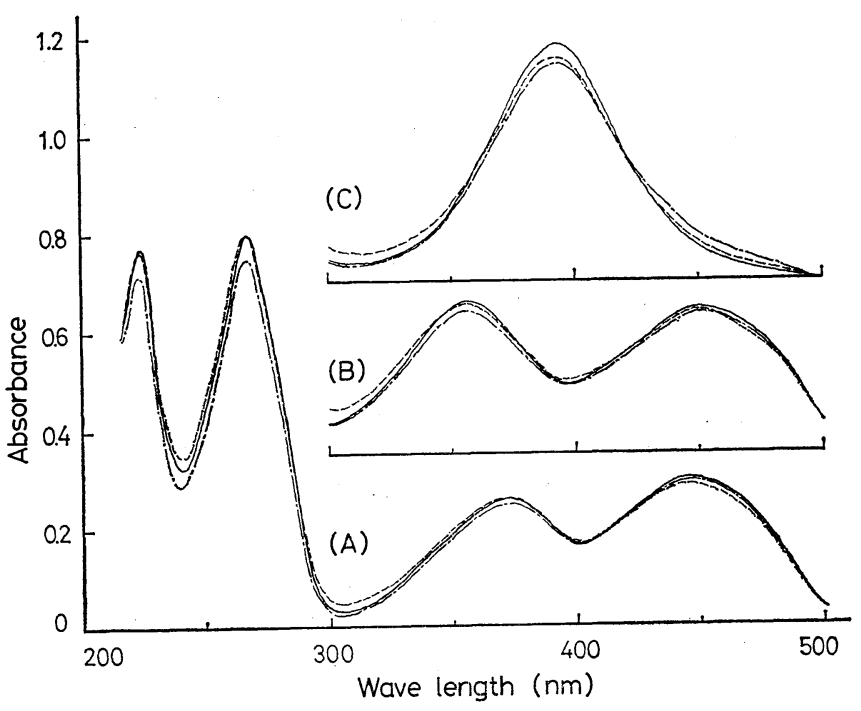

Fig. 1. UV and VIS absorption spectra of SF. (A): in water, (B): in $0.05 \mathrm{~N}$ sodium hydroxide, (C): in $3 \mathrm{~N}$ hydrochloric acid. —-, FR; -----, $\mathrm{SF}_{1} ;-\cdot-\cdot-, \mathrm{SF}_{2}$.

amined, in comparison with those of the first flavin, $\mathrm{X}$ or several known flavins. It may be due to a similarity of the paper chromatographic and electrophoretic behaviour between $\mathrm{Y}$ and FR that the existence of the new flavin, $\mathrm{Y}$ has not been detected hitherto. In a subsequent experiment, we found that $\mathrm{Y}$ was clearly distinguishable from FR by its behaviour in the bioassay using Lactobacillus casei ATCC 7469 (unpublished data). The compound Y or X had the general properties of a flavin, and was distinguished from FR, its known derivatives or photolysis products. Furthermore, $\mathrm{Y}$ as well as $\mathrm{X}$ was detected in the culture broth of all strains of Schizophyllum commune, so far tested. Therefore, these new flavins were named "schizoflavin (SF)" after Schizophyllum, and X and Y were tentatively called $\mathrm{SF}_{1}$ and $\mathrm{SF}_{2}$, respectively. The chemical structure and physiological function of SF should be clarified through further study.

\section{REFERENCES}

1) Tachibana, S., J. Vitaminol., 18, 210 (1972).

2) Tachibana, S. and Murakami, T., J. Ferment. Technol., 52, 511 (1974).

3) Crammer, J. L., Nature, 161, 349 (1948).

4) Tachibana, S., J. Vitaminol., 7, 294 (1961).

5) TAChibana, S., Vitamins (in Japanese), 40, 50 (1969).

6) TACHibana, S., Vitamins (in Japanese), 8, 356 (1955).

7) Salach, J., Walker, W. H., Singer, T. P., Ehrenberg, A., Hemmerich, P., Ghisla, S., and Hartmann, U., Eur. J. Biochem., 42, 2164 (1959).

8) MíasuoKa, M., Vitamins (in Japanese), 47, 13 (1973). 